\title{
EXISTE CORRELACIÓN ENTRE LA VELOCIDAD DEL FLUJO CAROTIDEO Y LA VELOCIDAD DE LA AORTA A LA SALIDA DEL VENTRICULO IZQUIERDO? ESTUDIO CON ULTRASONIDO
}

María Carolina Cabrera Schulmeyer ${ }^{1}$, Carolina Germakova ${ }^{2}$, Cristóbal Eggers ${ }^{3}$, Paulina Codoceo $^{4}$, Manuela Iweins $^{2}$, Rocio Armesto ${ }^{4}$

1 Universidad de Valparaíso, sede hospital Fach.

Universidad de Valparaíso, residente.

Universidad Mayor.

4 Universidad de Valparaíso.

Introducción: El ultrasonido (US) se ha convertido en una herramienta útil para los anestesiologos. Sin embargo, se requiere de diferentes grados de entrenamiento para su uso, ya sea en punciones venosas, bloqueos nerviosos o ecocardiografía. Ésta última aporta valiosos datos del estado hemodinámico de un paciente en manos de un operador entrenado, como es la velocidad máxima del flujo de salida a del ventrículo izquierdo (VMAO), que es un indicador directo del gasto cardíaco (GC).

Objetivo General: Se intentó correlacionar la velocidad máxima del flujo carotideo (VMFC), siendo este un lugar anatómico simple y fácil de estudiar, con la medición realizada con ecocar- diografía de VMAO.

Material y Métodos: Se estudiaron pacientes mayores de 18 años, previo consentimiento informado, ASA I. A todos los voluntarios se les midió PANI, FC y $\mathrm{SaO}_{2}$ basales y en posición supina. Luego se les realizó ecocardiografía transtorácica utilizando la ventana de 5 cámaras a nivel apical, con transductor cardiológico para medir la velocidad máxima aórtica del VI. De forma secuencial utilizando transductor lineal se midió a nivel de la carótida su velocidad máxima. Luego se posicionó al voluntario a $45^{\circ}$ por tres minutos y se repitieron todas las mediciones. Resultados: Se estudió un total de 55 voluntarios 6 fueron eliminados por no cumplir con los

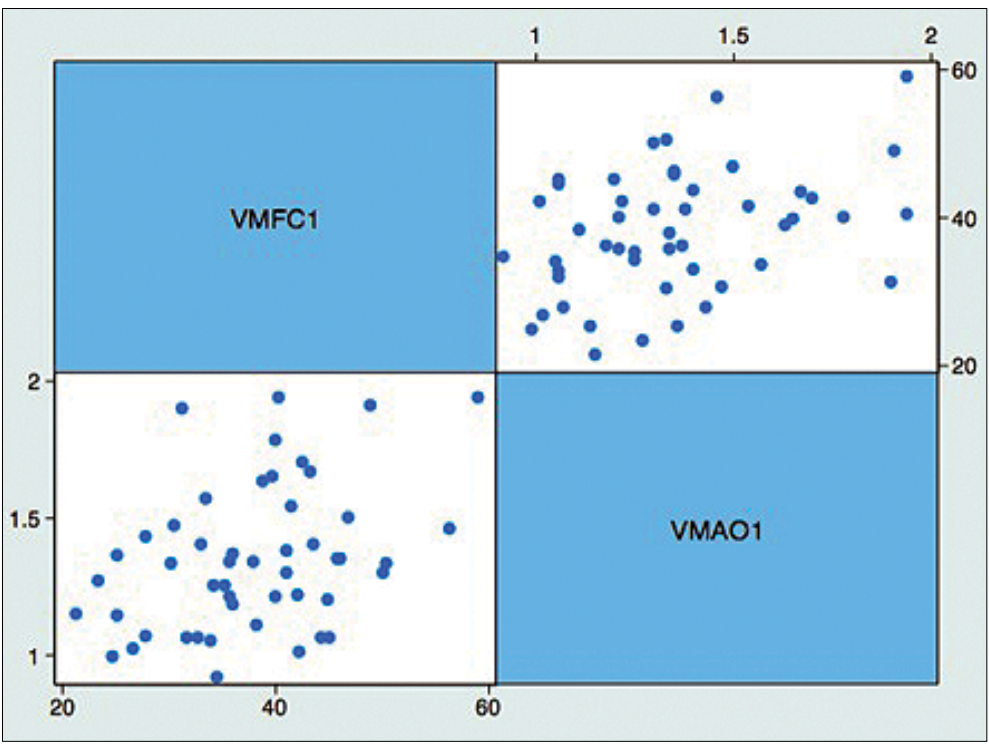

Figura 1. 
criterios de ingreso. La edad promedio fue de 29 años (rango 18 - 55), 29 mujeres. La distribución de edad, peso, talla PAM, FC y $\mathrm{SaO}_{2}$ fue normal (test de Shapiro Wilkinson). En supino a $0^{\circ}$ se obtuvo una correlación de Pearson con un $\mathrm{r}=$ $0,3769(\mathrm{p}=0,076)$ (figura 1$)$ y a $45^{\circ}$ la correlación mejoró a 0,4091 con un nivel de significancia de $\mathrm{p}=0,0035$ (figura 2).

Conclusiones: Se demostró que existió una buena correlación entre las velocidades máximas a nivel de la salida del VI y las velocidades en la carótida. Las principales ventajas de la medición de la velocidad a nivel de la carótida son su fácil acceso y que su entrenamiento para obtener los valores es muy simple y reproducible. Se demostró que esta correlación se observó a $0^{\circ}$ y luego de cambiar al voluntario a $45^{\circ}$ y así obtener alrededor de $500 \mathrm{ml}$ de autotransfusión. En conclusión, la medición de la velocidad del flujo a nivel de la carótida podría ser un buen parámetro para estudiar de manera indirecta el GC. Debe continuarse estudiando, eso sí, a pacientes portadores de patología cardíaca crónica y a pacientes sometidos a anestesia general. 